\title{
Energy-Efficient Oil-Water Separation of Biomimetic Copper Membrane with Multiscale Hierarchical Dendritic Structures
}

\author{
Zhiwu Han, Bo Li, Zhengzhi Mu, Shichao Niu, *Junqiu Zhang, and Luquan Ren
}

\begin{abstract}
Membrane-based materials with special surface wettability have been applied widely for the treatment of increasing industrial oily waste water, as well as frequent oil spill accidents. However, traditional technologies are energy-intensive and limited, either by fouling or by the inability of a single membrane to separate all types of oil-water mixtures. Herein, a biomimetic monolayer copper membrane (BMCM), composed of multiscale hierarchical dendritic structures, is cleverly designed and successfully fabricated on steel mesh substrate. It not only possesses the ability of energy-efficient oil-water separation but also excellent self-recovery anti-oil-fouling properties (<150 s). The BMCM even keeps high separation efficiency (>93\%) after ten-time cycling tests. More importantly, it retains efficient oil-water separation capacity for five different oils. In fact, these advanced features are benefited by the synergistic effect of chemical compositions and physical structures, which is inspired by the typical nonwetting strategy of butterfly wing scales. The findings in this work may inspire a facile but effective strategy for repeatable and antipollution oil-water separation, which is more suitable for various applications under practical conditions, such as wastewater treatment, fuel purification, separation of commercially relevant oily water, and so forth.
\end{abstract}

\section{Introduction}

Over the past few years, oil-water separation has become an increasingly important and urgent issue in modern chemical industrial process and environmental protection due to

Prof. Z. Han, Dr. B. Li, Dr. Z. Mu, Prof. S. Niu,

Prof. J. Zhang, Prof. L. Ren

Key Laboratory of Bionic Engineering

Ministry of Education

Jilin University

Changchun 130022, Jilin, P. R. China

E-mail: niushichao@jlu.edu.cn

Dr. Z. Mu

Department of Chemical Engineering

University of Michigan

Ann Arbor, MI 48109, USA

The ORCID identification number(s) for the author(s) of this article can be found under https://doi.org/10.1002/smll.201701121.

DOI: 10.1002/smll.201701121 increasing industrial oily wastewater, as well as frequent oil spill accidents. ${ }^{[1-6]}$ Many different approaches have been utilized for the oil-water separation purposes, including combustion, filtration, ${ }^{[7-9]}$ oil skimmers, ${ }^{[10,11]}$ magnetic separations, ${ }^{[12-14]}$ flotation technologies, ${ }^{[15,16]}$ oil-absorbing materials, ${ }^{[17-19]}$ and so on. Most of these methods involve harsh conditions and have a limitation for the types of oily water being treated. Taking all factors into account, membranebased strategies are attractive for the valid removal of a wide range of industrial effluents. ${ }^{[2]}$ Stainless steel mesh is widely used as basement membrane due to its porous structures and popular prices. ${ }^{[20]}$ In the past several years, there are a lot of methods having been reported for processing stainless steel mesh to prepare interface materials with oil-water separation function, such as chemical etching, ${ }^{[21]}$ sol-gel method, ${ }^{[2]}$ electrophoretic deposition, ${ }^{[23,24]}$ zeolite-coated method, ${ }^{[25]}$ chemical vapor deposition (CVD) method, ${ }^{[26-28]}$ and so on. Although these strategies are feasible for achieving oil-water separation function, there are some disadvantages that need to be overcome, such as pore 
clogging and surface oil-fouling, which lead to reductions in separation efficiency.

After billions of years of evolution, creatures in nature possess almost perfect structures and surface functions. Nature has experimented with various solutions to its challenges and has improved the successful ones, which can provide ready answers to scientific and technical problems and inspire us with a series of novel designs and high-performance structures. Abundant and gorgeous species in nature have been investigated and mimicked for many years aiming to design unique structured materials with excellent functions and extensive practical values. ${ }^{[29-31]}$ In particular, increasing interests have been directed to bio-inspired nonwetting surfaces, such as lotus leaves, ${ }^{[32]}$ rose petals, ${ }^{[33]}$ water striders, ${ }^{[34]}$ and so on. To a certain extent, existing biomimetic surfaces also relieve the limitation for the oil-water separation of various oil-water mixtures and possess the anti-oil-fouling properties. However, the underlying mechanism is not very clear and unified so far. ${ }^{[35]}$ As a typical hotspot of the bionic field recently, buttery wings are endowed with a diversity of excellent properties. ${ }^{[36-41]}$ Wings of butterfly exhibit either static or vibrating states in their daily life. No matter in which kind of state, butterfly need light-loaded wings to ensure the flexibility of their flying. On the one hand, for the butterfly in rainforest, water droplets are often dropped down upon butterfly wings. Therefore, butterfly has evolved to a nonwetting surface on the wings. On the other hand, butterfly also need prevent oil secreted by the trees from adhering on their wing surfaces during the flight. Therefore, it is necessary for butterfly to make oil droplets volatilized as soon as possible. In a word, butterfly wings possess excellent nonwetting property, which provides inspiration and opens up an avenue for the realization of oil-water separation function.

In this work, the typical nonwetting performance of the Trogonoptera brookiana butterfly wings was demonstrated. Inspired by its oil-water separation mechanism, the multiscale hierarchical dendritic structure (MHDS)-based BMCM was successfully fabricated via a simple and effective method that combined electroless deposition and subsequent chemical modification. The dimensions and distributions of SNWF in BMCM were characterized. The nonwetting properties of MHDS-based BMCM were investigated experimentally. Meanwhile, a set of optimized models was generated. Moreover, the cycling tests demonstrated that BMCM possessed excellent recyclability because the separation efficiency remained higher than $93 \%$ for five different oils after more than ten-time repeats. Anti-oil-fouling behaviors of the BMCM were also examined carefully. It was confirmed that the BMCM possesses superior self-recovery anti-oil-fouling property ( $\approx 150 \mathrm{~s})$. Hence, the anti-oil-fouling performance and the applicability to multiple oils of the BMCM suggested great potential value for solving the issues of oil-water separation materials, such as pore clogging and surface oil-fouling.

\section{Results and Discussion}

In this work, T. brookiana butterfly was selected as the biological prototype for its typical humid habitat. In fact, it is
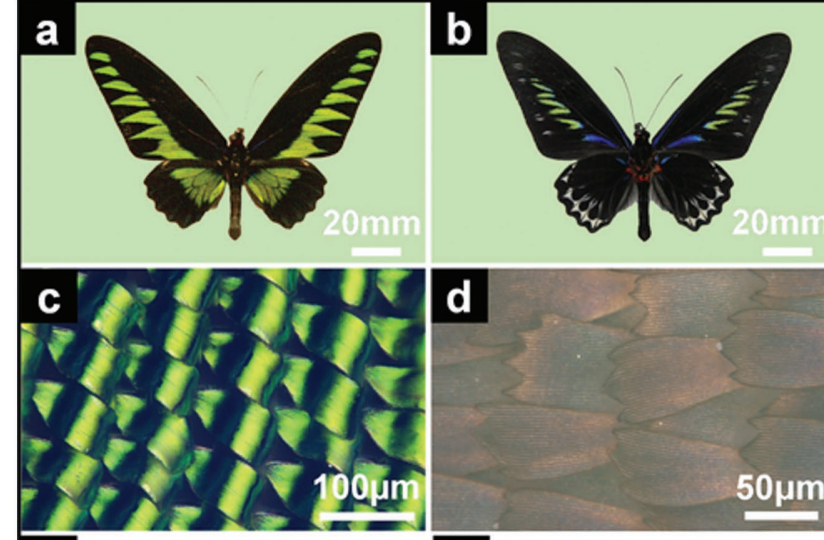

d
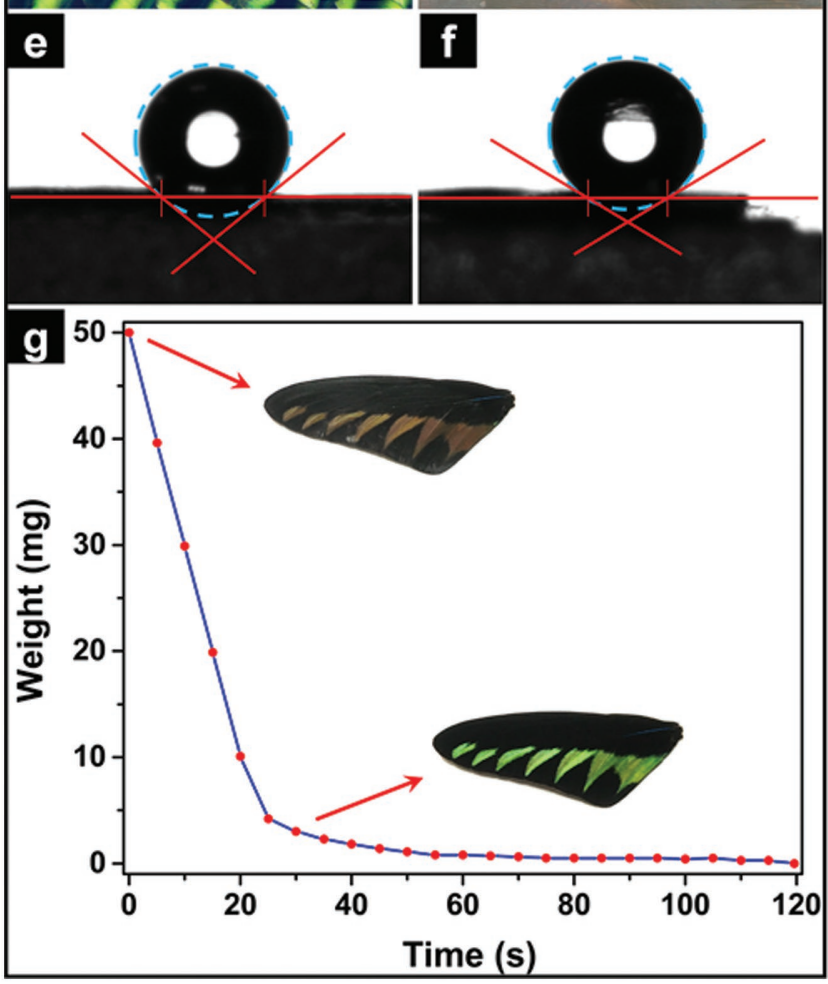

Figure 1. Wettability and self-recovery anti-oil-fouling properties of Trogonoptera brookiana butterfly. a,b) Digital images of the original female butterfly. c,d) Stereoscopic microscopy images of green and black regions. e,f) Water contact angle of green and black regions. g) Self-recovery anti-oil-fouling property of butterfly wings. Butterfly wings recover to initial oil-free state for $\approx 30 \mathrm{~s}$.

distributed across a wide range of tropical rainforests in the world, especially Southeast Asia. Figure 1a,b showed the overall view of the original butterfly. It could be observed clearly that triangular green patches and gorgeous metallic black areas distributed on fore and hind wings using digital camera. With the help of optical stereo microscope, the brilliant scales lined up and the micro morphologies of the wing scales were observed as shown in Figure 1c,d. These scales were placed in alternate rows and overlapped each other. This kind of arrangement ensured that these scales formed a dense film on butterfly wing surface. Afterward, the wetting behaviors of water on butterfly wings were further evaluated using an optical contact angle (CA) measuring device. The water droplets stayed spheroidal on the wing surface. The 


\section{ADVANCED SCIENCE NEWS}

www.advancedsciencenews.com

water CAs of green and black parts were $148.4^{\circ}$ (Figure 1e) and $152.7^{\circ}$ (Figure 1f), respectively. So, it could be indicated that the hydrophobic performance of black region was better than that of green region. Interestingly, the butterfly wings not only possessed superhydrophobic property but also showed self-cleaning feature as shown in Video S1 (Supporting Information). They worked together to be responsible for the waterproof capability. Wetting behavior of oil on front butterfly wings was examined carefully. $50 \mathrm{mg}$ oil was added dropwise onto butterfly wings through a glass capillary. Oil droplets spread out over the whole surface uniformly and the oil contact angle was about $0^{\circ}$, which showed the superoleophilic property of butterfly wing. During the process, butterfly wings were placed on a high-sensitivity electronic balance. At the same time, a high-speed camera was utilized to record the readings of electronic balance. Figure $1 \mathrm{~g}$ showed the residual oil as a function of time $t$. About $30 \mathrm{~s}$ later, oil droplets were completely released and butterfly wings reverted to the original state. It was confirmed that butterfly wings possessed superior self-recovery anti-oil-fouling property $(\approx 30 \mathrm{~s})$, which was conducive for butterfly to keep their wings light-loaded for flexible flight.

To examine liquid wetting behaviors of butterfly wings more intuitively, a high-speed camera system (Figure S1, Supporting Information) was used to record bounce dynamics of water droplets (radius $R=1.58 \mathrm{~mm}$, velocity $U=0.87 \mathrm{~m} \mathrm{~s}^{-1}$ ) and spreading processes of oil droplets (radius $R=1.16 \mathrm{~mm}$, velocity $U=0.89 \mathrm{~m} \mathrm{~s}^{-1}$ ) as shown in Figure 2. On butterfly wing surface, the impacting water droplets viewed from the side (up of Figure 2a,b) spread to a film, retracted, and then lifted off within just 12.33 and $21.33 \mathrm{~ms}$, respectively. Little contact time between water droplets and butterfly wings proved that butterfly wings had a fine ability to resist water. In addition, the overall contact time of black part was much less than that of green part, which confirmed the better water repellency. So, black region was chosen as the experimental area for further examination. Synchronized top-view images (down of Figure 2a,b) showed faster retraction along the
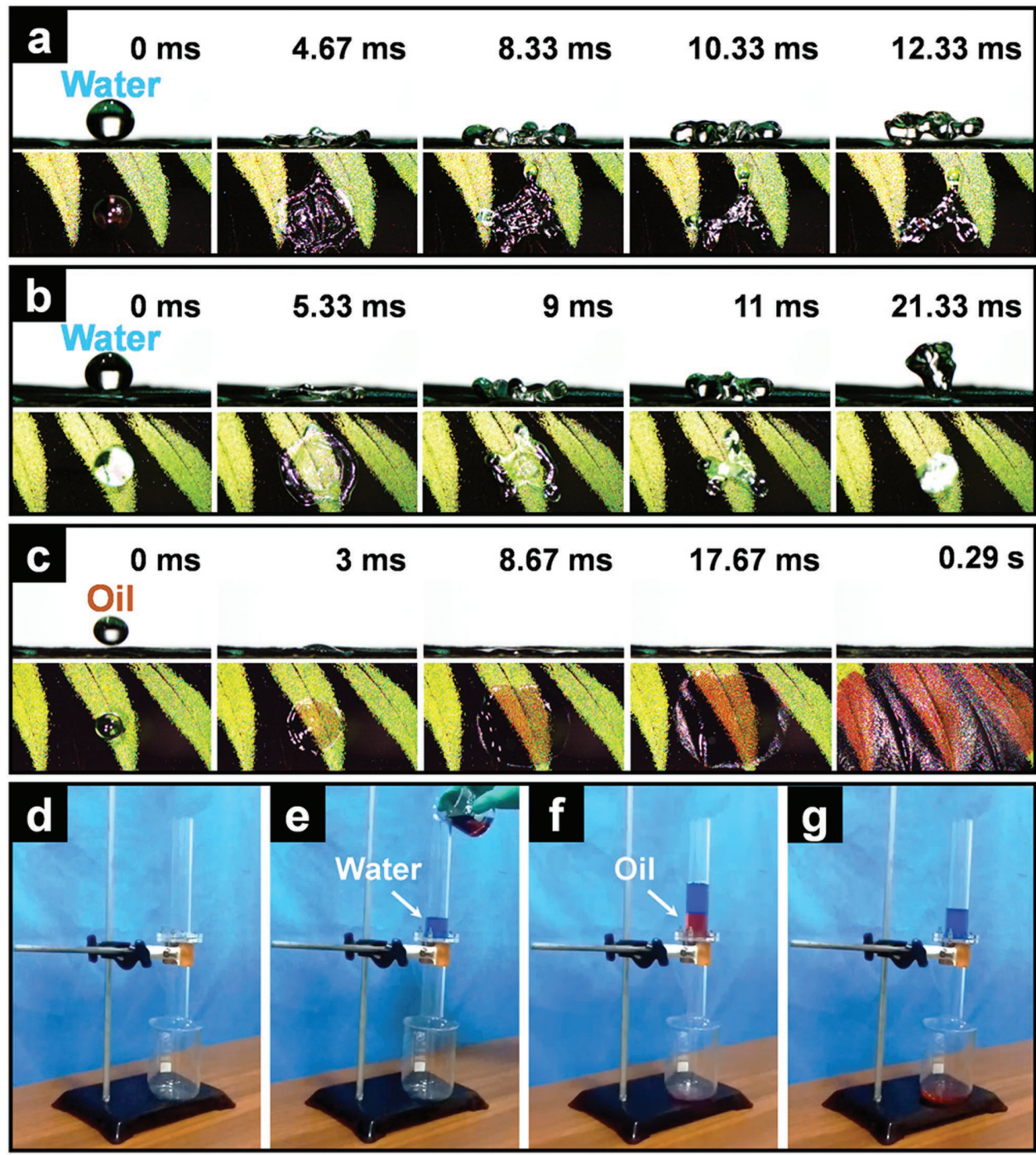

Figure 2. Water bounce dynamics, oil spreading processes, and oil-water separation processes on butterfly wing surfaces. a) Bounce dynamics of a water droplet impacting with the green regions. b) Bounce dynamics of a water droplet impacting with the black regions. c) Spreading processes of an oil droplet impacting with the butterfly wing surface. d) Before, e,f) among, and g) after the oil-water separation processes. The oil and water are dyed with Sudan III and methylene blue, respectively. 
ridge than in other directions. This variation in speed broke the radial symmetry of the recoiling film, causing the liquid to move rapidly inward along the ridge. More film would participate in the recoil. This was the reason of the less contact time between butterfly wings and water droplets. The oil wettability was characterized then (Figure 2c). When an oil droplet was dropped onto the wing surface, it spread out quickly and CA reached near $0^{\circ}$. The whole process was completed within $0.3 \mathrm{~s}$, suggesting a superior property of the surface for oil wetting. Figure $2 \mathrm{~d}-\mathrm{g}$ showed that butterfly wing possessed oil-water separation capability, which was proved by a gravity-driven oil-water separation process. A piece of butterfly wing was fixed between two teflon flanges. Water was colored with methylene blue while oil (chloroform) was colored with Sudan III to aid visualization, which did not alter the wettability behaviors. A mixture of oil and water was poured into a glass tube connected with teflon flange. Oil spread and permeated butterfly wing surface rapidly due to the superoleophilicity, whereas water was repelled and retained in the
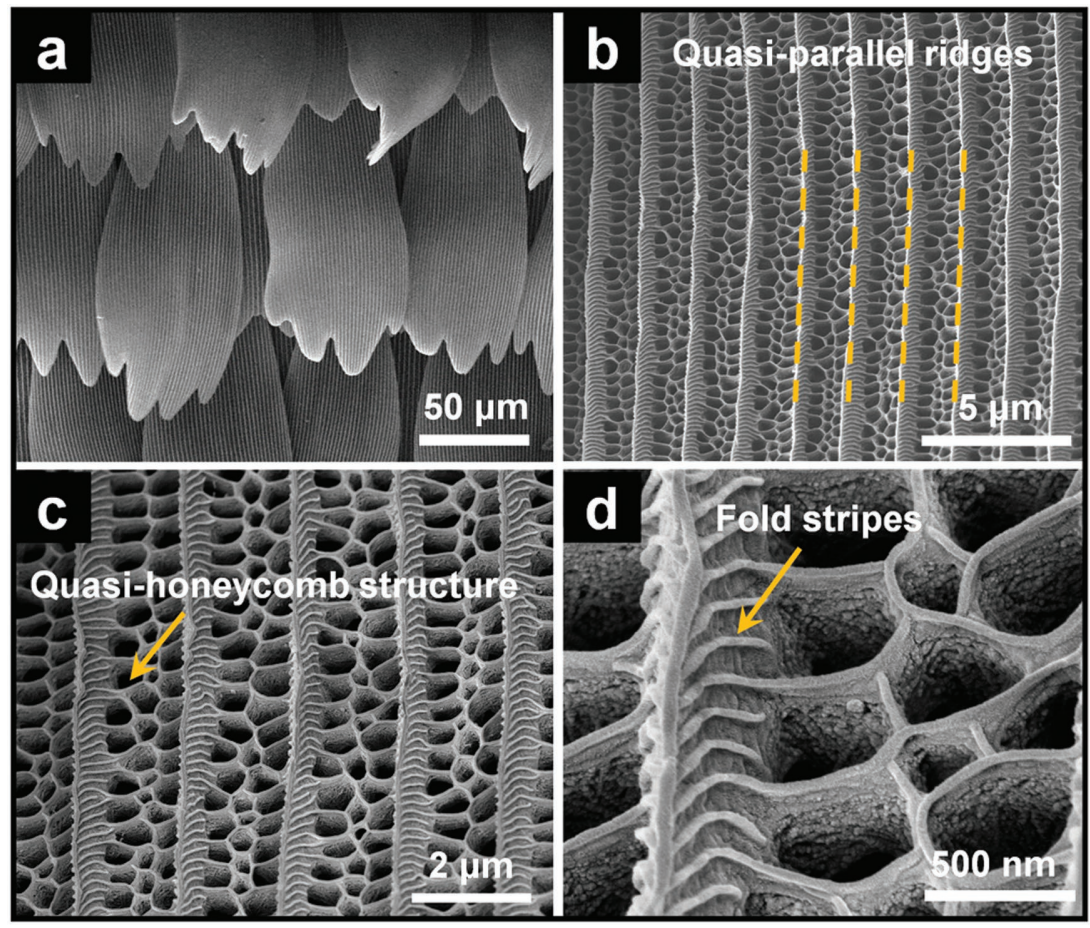

Figure 3. Structural analysis of the original butterfly wings. a) Scales range in good order on the substrate. b,c) Scale surface comprises a set of raised longitudinal quasi-parallel lamellae (ridges). The space between ridges is filled with a quasi-honeycomb structure. d) There are fold stripes distributing on both sides of ridges. teflon flange above butterfly wings owing to the superhydrophobicity. Little water was found in the collected oil, indicating the high separation efficiency of butterfly wings (Video S2, Supporting Information). However, it was a pity that the separation rate was a little low. The possible reason maybe that the pores on butterfly wing surface were too small.

In order to clarify the reasons why butterfly wings possessed oil-water separation function, we investigated chemical compositions and physical structures of butterfly wing surface. The wingspan of a male $T$. brookiana butterfly was $\approx 12 \mathrm{~cm}$, and the dorsal wings consist of overlapping scales with mysterious brilliance (Figure 1). It was clearly found that these scales ranged in good order on the substrate under low magnification (Figure 3a). The scales resembled the rooftop tiles very much in shape with $\approx 160 \mu \mathrm{m}$ in length and $70 \mu \mathrm{m}$ in width. The root of each scale was embedded on the substrate. More exquisite structures were observed under medium magnification as shown in Figure 3b,c and Figure S2 (Supporting Information). It could be observed that the scale surface comprised a set of raised longitudinal quasi-parallel lamellae (ridges). The distance between two adjacent ridges was $\approx 1.5 \mu \mathrm{m}$. The space between adjacent ridges was filled with a netlike reticulum composed of pores. It was called a quasi-honeycomb-like structure. Figure 3d showed the high-magnification images of the quasi-honeycomb-like structures. It could be observed that there were parallel fold stripes on both sides of the ridges. Ridges and fold stripes formed the structural nonwetting framework (SNWF in Figure S2, Supporting Information) of butterfly wing scales.
The chemical elements and content analysis of butterfly wing surface were characterized by energy-dispersive spectrometer (EDS). The major elements included carbon (C), hydrogen $(\mathrm{H})$, oxygen $(\mathrm{O})$, and nitrogen $(\mathrm{N})$, which constituted the nonwetting organic framework of butterfly wings as shown in Figure 4a. Feature peaks of $\mathrm{C}$ and $\mathrm{N}$ were observed clearly, and the atomic percentages of these two elements were 71.54 and $7.02 \%$, respectively. In the X-ray diffraction (XRD) spectrum (Figure 4b), a strong Bragg peak appeared at $11.25^{\circ}$, which further confirmed the periodic character of original butterfly wings. When it comes to the chemical compositions, Fourier transform infrared spectrum (FTIR) was employed to analyze the chemical bonds of the SNWF in butterfly wing scales. As shown in Figure 4c, the enhanced absorption peaks of butterfly specimen appeared at 667 and $2358 \mathrm{~cm}^{-1}$, which were attributed to the bending vibration and asymmetric stretching vibration of carbon dioxide. The broad absorption peaks at 3428 and $3260 \mathrm{~cm}^{-1}$ correspond to the stretching vibration of hydroxyl groups $(-\mathrm{OH})$ and the $\mathrm{N}-\mathrm{H}$ bond, respectively. The weak absorption peaks at 2966, 2923, and $2874 \mathrm{~cm}^{-1}$ were assigned to the stretching vibration of the $\mathrm{C}-\mathrm{H}$ bond. The multipeaks at 1655,1550 , and $1310 \mathrm{~cm}^{-1}$ around the fingerprint region were assigned to amide I, amide II, and amide III, which were the characteristic groups of chitin. The weak peak around $1076 \mathrm{~cm}^{-1}$ was assigned to the stretching vibration of the $\mathrm{C}-\mathrm{O}$ bond and the very weak peak around $886 \mathrm{~cm}^{-1}$ was assigned to the stretching vibration of the hexatomic ring, which was the backbone of chitin. In conclusion, the original scales in butterfly wings were mainly chitin-based and primarily composed of water-insoluble organic components. 

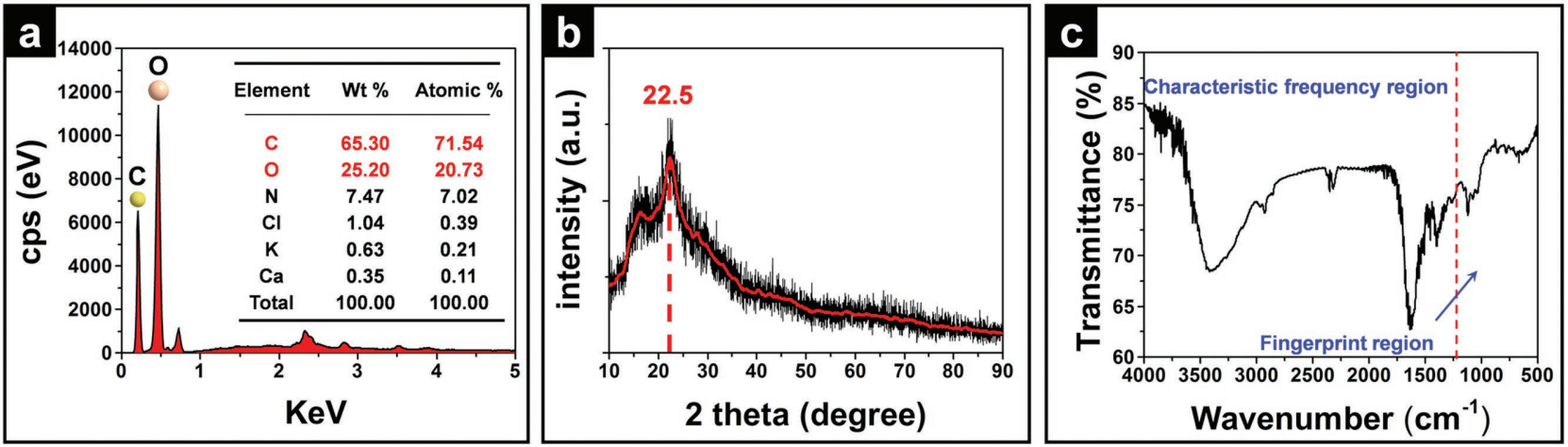

Figure 4. Chemical composition analysis of the original butterfly wings. a) EDS spectrum. The EDS spectrum provides the element types and content analysis. b) XRD patterns. A strong Bragg peak confirms the periodic character of micro-/nanostructures in original butterfly wings. c) FT-IR spectrum. Butterfly wings are mainly chitin-based and primarily composed of water-insoluble organic components.

According to the feature sizes of wing scales, visual 3D optimized configuration models were built to illustrate the nonwetting mechanism in butterfly wing scales (Figure 5). On the one hand, microscale ridges on butterfly wing surface made contributions to water repellency as displayed in Figure 5b,c. These ridges provided a certain degree of roughness for scale surface and allowed the trapping of a thin air layer, which avoided the penetration of water into this welldefined region and enhanced superhydrophobic property of butterfly wings. As for oil droplets, penetration of oil into air layer required less energy due to low surface tension. On the

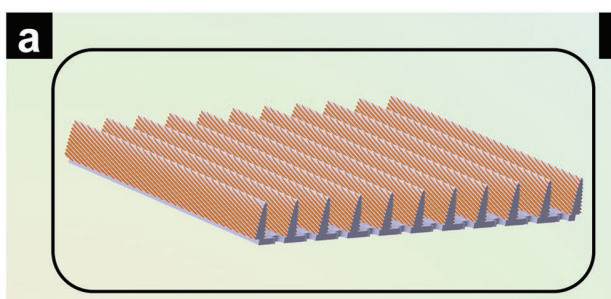

The SNWF model
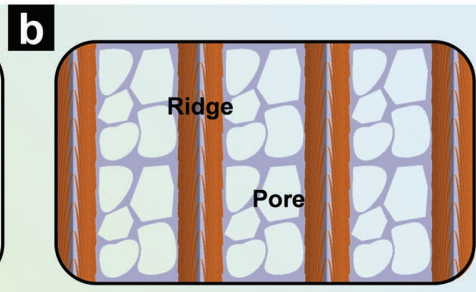

Vertical view

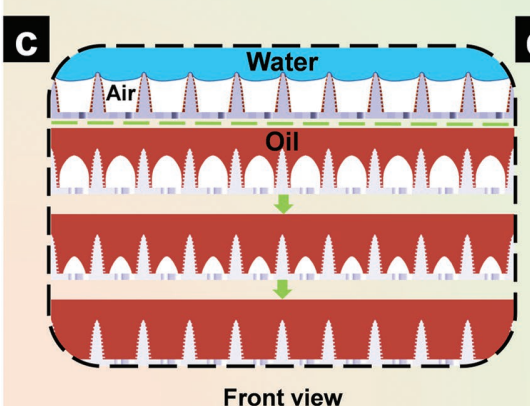

Front view

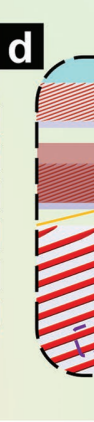

other hand, nanoscale fold stripes were conducive to superhydrophobic, superoleophilic, and self-recovery anti-oilfouling properties (Figure $5 \mathrm{~d}$ ). These fold stripes distributing on both sides of the ridges constituted a set of channels (the space between fold stripes). Since the channels were composed of chitin and water-insoluble organic components, a lot of hydrophobic groups were distributed on the side wall of channels. The presence of these groups allowed oil molecules to pass, while the water molecules were repelled. These features made the space between fold stripes form selective liquid channels (SLCs) as shown in Figure 5e. The SLCs allowed oil droplets flow rapidly along the ridge until oil droplets filled the air layer, and then passed through the pores in the scales. In a word, T. brookiana butterfly could smartly and efficiently handle this puzzle via the roughness effect and hydrophobic groups in its wing scales. In terms of structural nonwetting framework (combination of the ridges and fold stripes) and chemical composition (water-insoluble organic components) of butterfly wing, they inspired us to design and implement a biomimetic oil-water separation surface.

The following work was the biomimetic fabrication process of SNWFbased monolayer membrane. Stainless steel mesh was an ideal basement membrane for its popular prices as well as its porous structures that corresponded to the SNWF ${ }^{[20]}$ A simple and effective two-step synthesis approach was used, combining an electroless deposition method and chemical modification process. A kind of biomimetic monolayer copper membrane $(\mathrm{BMCM})$ was generated. The fabrication process was illustrated briefly (Figure 6a), and the corresponding internal chemical synthesis mechanism was described intuitively (Figure 6b-d). When stainless steel meshes were soaked in copper chloride solution, elemental iron $(\mathrm{Fe})$ in steel wires 

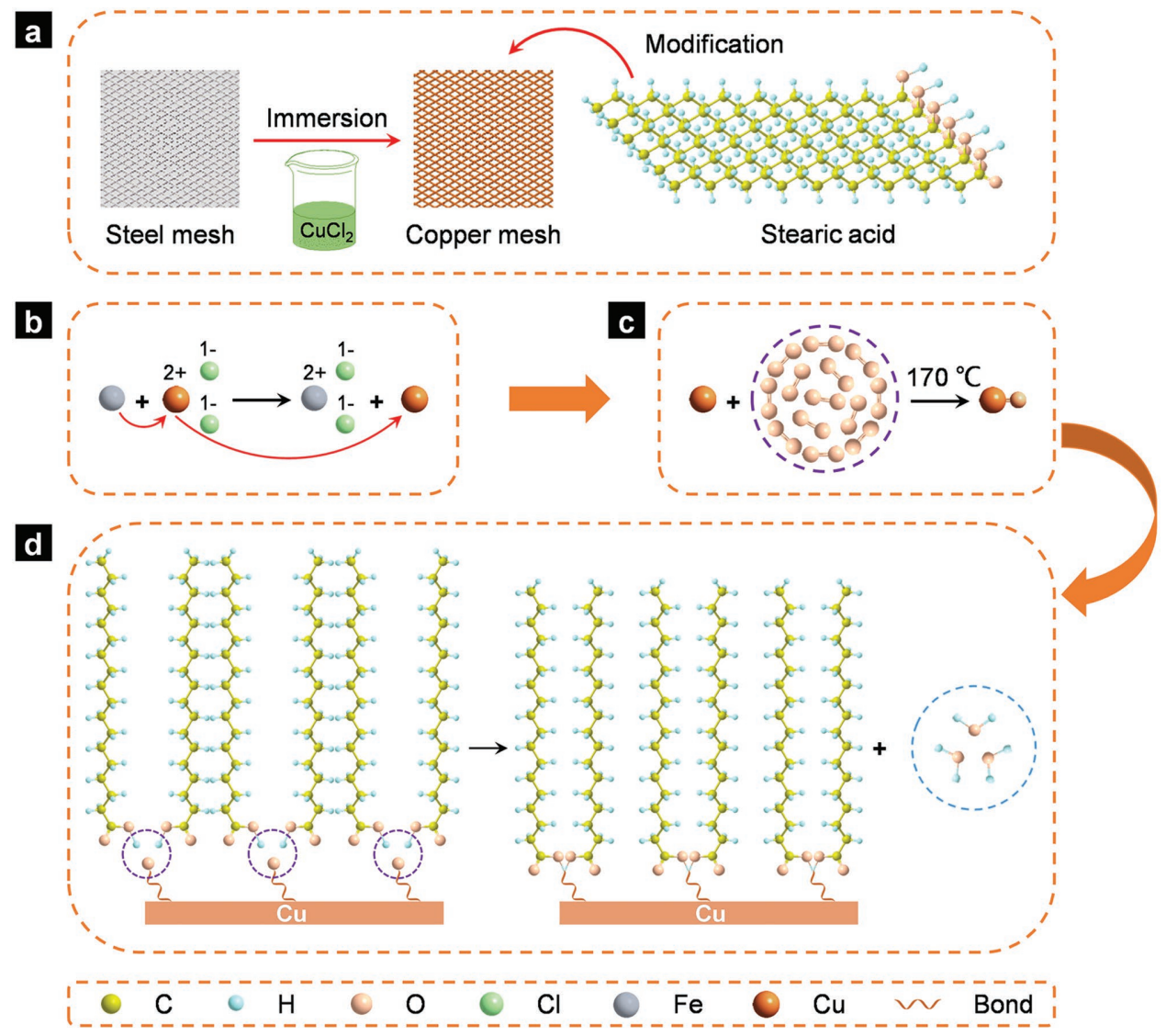

Figure 6. Bioinspired fabrication process of the MHDS-based BMCM and the internal chemical synthesis mechanism. a) The construction process of MHDS on stainless steel mesh. b) The ion-exchange process involved in electroless deposition. This process leads to the growth of copper on stainless steel mesh. c) Copper reacts with oxygen, producing copper oxide under hydrothermal condition. This process synthesizes receptors for stearic acid. d) Copper stearate 3D networks are gradually formed and extend along the MHDS-based BMCM via the double decomposition reaction.

surface would be replaced by copper ion $\left(\mathrm{Cu}^{2+}\right)$ (Figure 6b). The steel wire surface presented micro-/nanoscale hierarchical structures due to the self-growing of $\mathrm{Cu}$. Afterward, the as-prepared copper meshes were placed in the vacuumdrying oven. Oxidation reaction between $\mathrm{Cu}$ and $\mathrm{O}_{2}$ occurred to form the copper oxide $(\mathrm{CuO})$ in the hydrothermal condition (Figure 6c). Then, the pretreated copper meshes were modified with a $0.1 \mathrm{~m}$ ethanol solution of stearic acid for 80 min under ambient conditions. The hydrophobic alkyl chains $\left(\mathrm{CH}_{3}\left(\mathrm{CH}_{2}\right)_{16} \mathrm{COO}-\right)$ could be chemically grafted at the native oxide surface of copper meshes via the double decomposition reaction, generating a self-assembled monolayer (Figure 6d). In fact, the displacement reaction and double decomposition reaction together constituted the main body of the aforementioned chemical synthesis mechanism.

Figure 7a and Figure S3 (Supporting Information) showed a typical image of the pristine stainless steel mesh with single-layer steel wires, which formed a series of square pores. The inset showed that the surface of steel wire was quite flat. As shown in Figure 7b-d, BMCMs were covered with not only the microscale steel wires and copper clusters but also numerous nanoscale dendritic bumps, forming the typical MHDSs. The copper clusters covered the steel wires uniformly and almost no redundant $\mathrm{Cu}$ blocked the mesh pores, which ensured liquid passed through BMCMs freely. The thickness of the copper clusters was $\approx 30 \mu \mathrm{m}$. The role of micrometer clusters was equivalent to ridges on butterfly wings, which could support the water film and form an air layer in the region between the top of copper clusters and steel wire surface. In addition, it could be found from the high-resolution scanning electron microscopy (SEM) images viewed from side (Figure 7d) that the copper clusters were composed of numerous nanoscale projections. Copper clusters and dendritic bumps formed the SNWF of BMCM together. These nanoscale dendritic bumps together with a monolayer of copper stearate 3D networks formed SLCs, which acted like fold stripes on butterfly wings (see Figure 3). To determine the average roughness, a 3D microscope system with superwide depth of field was used to measure the surface roughness of the steel mesh (Figure 7e) and the BMCM (Figure 7f). Through comparing the topological differences, it was found that the surface roughness of the BMCM was increased obviously after modification. The BMCM showed an average mean square roughness ( $\mathrm{Ra}$ ) of $25.952 \mathrm{~nm}$, which is much higher than that of stainless steel mesh $(17.486 \mathrm{~nm})$ within the same area scanned. This is due to the existence of dendritic structures on the BMCM surface, which could increase the surface roughness and hierarchy. ${ }^{[42,43]}$ Chemical composition analysis of BMCM was carried out using EDS and XRD. Figure 7e showed the EDS spectra of the BMCM. The appearance of elemental $\mathrm{C}, \mathrm{O}$, and $\mathrm{Cu}$ indicated that $\mathrm{Fe}$ of steel wires displaced the copper ions in the copper chloride 

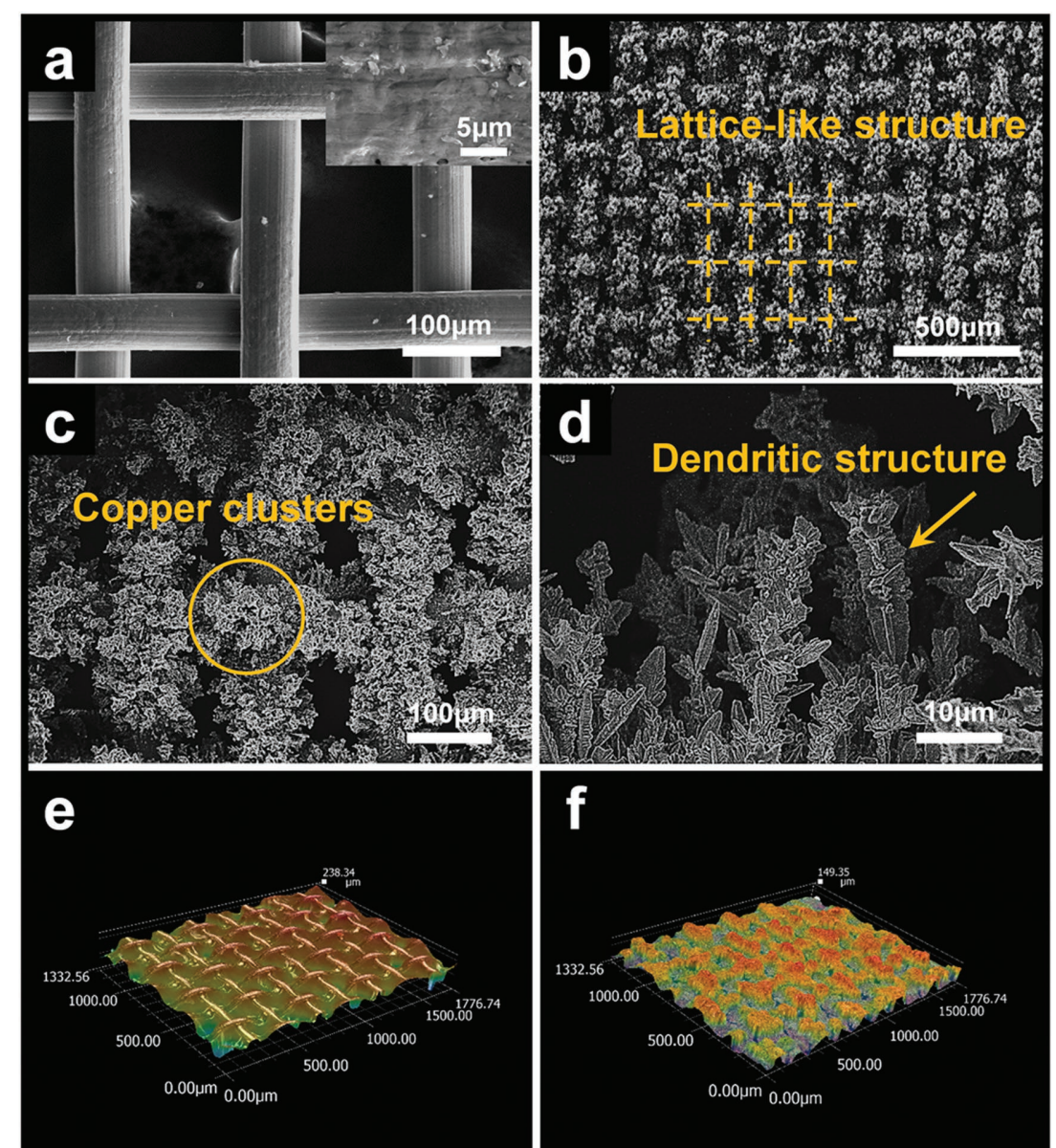

g

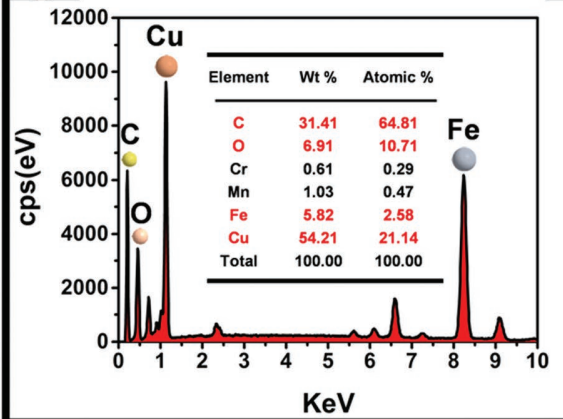

\section{h}

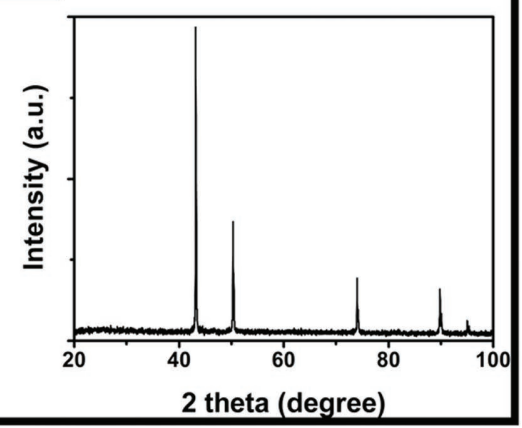

Figure 7. Structural and chemical composition analyses of MHDS-based BMCM. a) FESEM images of original stainless steel mesh. The inset shows that the steel wire surface is flat. b) Low-magnification FESEM images demonstrate overall morphology of MHDS-based BMCM, especially the lattice-like structures. c) Enlarged FESEM images display microstructures of the bioinspired MHDSs, which act like ridges on butterfly wings. d) FESEM image of bioinspired dendritic structure from the side view under high magnification. Images showing the surface roughness of samples e) stainless steel mesh and f) BMCM. g) EDS spectrum indicates that the main elements of BMCM are $\mathrm{Cu}, \mathrm{C}, \mathrm{Fe}$, and $\mathrm{O}$, which further demonstrates that the $\mathrm{Cu}$ has generated on steel mesh successfully. h) XRD patterns. XRD spectrum of MHDS presents its quasi-PC structures and corresponding grazing angles.

solution and SNWF was modified by stearic acid successfully. The XRD pattern (Figure 7f) further revealed that the BMCM was crystallized. It also indicated that the copper was self-growing on the steel wires surface. The five distinct peaks appearing in the spectra were assigned to copper stearate $\left(\mathrm{Cu}\left[\mathrm{CH}_{3}\left(\mathrm{CH}_{2}\right)_{16} \mathrm{COO}\right]_{2}\right)$, resulting from a reaction between stearic acid $\left(\mathrm{CH}_{3}\left(\mathrm{CH}_{2}\right)_{16} \mathrm{COOH}\right)$ and copper oxide. The appearance of the copper stearate peaks confirmed the presence of low surface energy methylated $\left(-\mathrm{CH}_{3}\right.$ and $\left.=\mathrm{CH}_{2}\right)$ components on BMCM.

The water bounce dynamics on BMCM were recorded with the help of a high-speed video camera, when a $16.7 \mu \mathrm{L}$ water droplet was dropped from a height of $40 \mathrm{~mm}$ (Figure 8a). The dropping height was determined by the maximum height avoiding the droplet fragmentation when impacting with the surface, ensuring maximum droplet momentum. The droplet volume $(\approx 17 \mu \mathrm{L})$ was found to be optimum as the droplet could be replicated easily and fell under its own weight when dropped from a 23 gauge dispensing tip. The observations showed that water droplets spread out quickly in the immediate aftermath of impacting with BMCM. The initial impacting velocity of droplet was $0.86 \mathrm{~m} \mathrm{~s}^{-1}$. At $4.67 \mathrm{~ms}$, the area of the water film reached a maximum. Then, the water droplet rapidly shrank and was completely removed from surface of the BMCM within $22.33 \mathrm{~ms}$, which illustrated excellent superhydrophobic and selfcleaning properties. The water droplets impacting tests were also performed on the pristine steel mesh film for comparison (Figure $8 b$ ). The pristine steel mesh showed hydrophilic and adhesive properties toward water, and the water was confined on the surface without bouncing out. The examination of oil droplets impinging BMCM was also carried out (Figure 8c). The dropping height was $40 \mathrm{~mm}$ and the diameter of oil droplets was $\approx 2.33 \mathrm{~mm}$. Oil droplets were also dropped from a 23 gauge dispensing tip. Parameters mentioned above were determined in the same manner as the water droplet impacting tests. The observations showed that oil droplets impacted BMCM and spread out quickly. The initial impacting velocity of the droplet was $0.84 \mathrm{~m} \mathrm{~s}^{-1}$. At $22.33 \mathrm{~ms}$, the oil droplets infiltrated the BMCM completely and the oil film area reached a maximum, denoting an intrinsic superoleophilic property. Oil droplet impacting tests were also performed on the pristine steel mesh film for comparison. (Figure 8d). The pristine steel mesh required $117.33 \mathrm{~ms}$ to be infiltrated absolutely, which was much more than that of BMCM.

As shown in Figure 9a-d, the separation of water-oil mixtures was realized using the BMCM-based device. Here, a piece of BMCM $\left(5 \times 5 \mathrm{~cm}^{2}\right)$ was applied to separate oil 


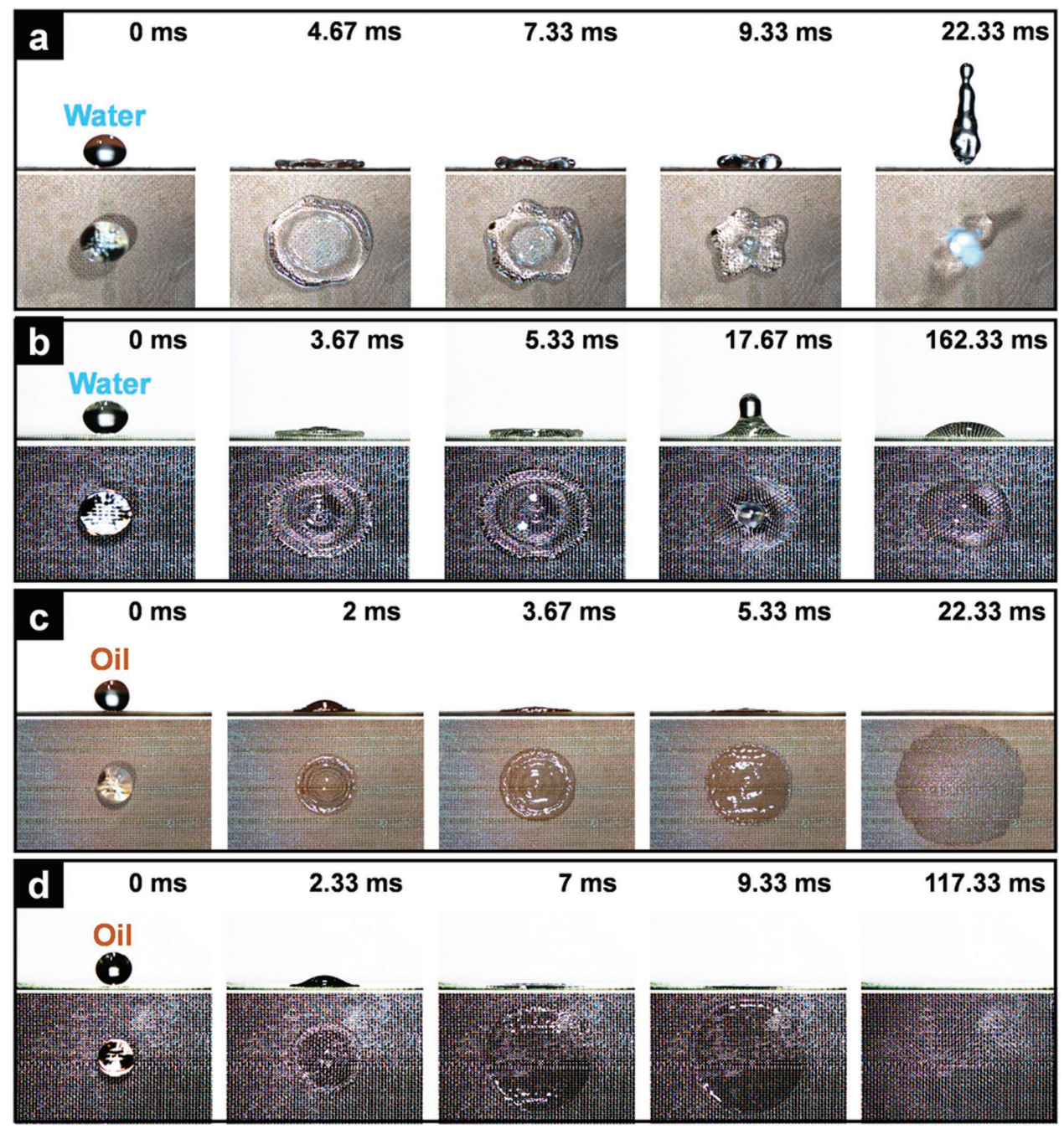

Figure 8. Water bounce dynamics and oil spreading processes on MHDS-based BMCM and original steel mesh. a) Bounce dynamics of a water droplet impacting with MHDS-based BMCM. b) Bounce dynamics of a water droplet impacting with original steel mesh. c) Spreading processes of an oil droplet impacting with MHDS-based BMCM. d) Spreading processes of an oil droplet impacting with original steel mesh.

(dyed in red with Sudan III) from water (dyed in blue with methylene blue). The MHDSs-based BMCM was fixed between two steel flanges. Then, the oil-water mixtures were poured into the glass tube connected with flanges. It could be observed that the oil permeated through the BMCM rapidly and dropped into the beaker underneath, whereas the water was still retained in the glass tube upon BMCM (Videos S3-S5, Supporting Information). The experimental results illustrated the efficient separation ability of BMCM for water-oil mixture. The oil-water separation efficiency was used to describe the oil-water separation ability. The impact of repeated times of oil-water separation processes on the separation efficiency was investigated to evaluate reusability. The oil-water separation efficiency ( $R$, expressed as a percentage) was then calculated based on the following equation:

$R(\%)=\left(1-\frac{C_{\mathrm{P}}}{C_{\mathrm{O}}}\right) \times 100$

Herein, $C_{\mathrm{O}}$ and $C_{\mathrm{P}}$ were the oil concentration of the original oil-water mixtures and the collected water after the first separation. The oil concentration was measured using an automatic infrared oil analyzer. As shown in Figure 9e, BMCM remained efficient (>93\%) for five different oilwater mixtures after the experiment has been applied for ten cycles, indicating the excellent recyclability of BMCM (Table S1, Supporting Information). The deficit in the collected amount compared with the original amount was mostly absorbed by the device itself, and a small amount oil remained inside the beaker and glass tube. There were slight differences of separation efficiency between different types of oil. This might be attributable to the different density and adhesion of oil. This route required no external force but only gravity of oil-water mixtures in the separation processes, which means it has the merit of low-energy consumption. As shown in Figure S5 (Supporting Information), the contact angle of BMCM before the oil-water separation was $154.3^{\circ}$. As-prepared BMCM remained superhydrophobic $\left(\mathrm{CA}=151.5^{\circ}\right)$ after the oil-water separation experiment had been applied for ten cycles. It also denoted that as-prepared BMCM shows excellent recyclability for oil-water separation. Then, the ability of BMCM recovering to an oil-free 

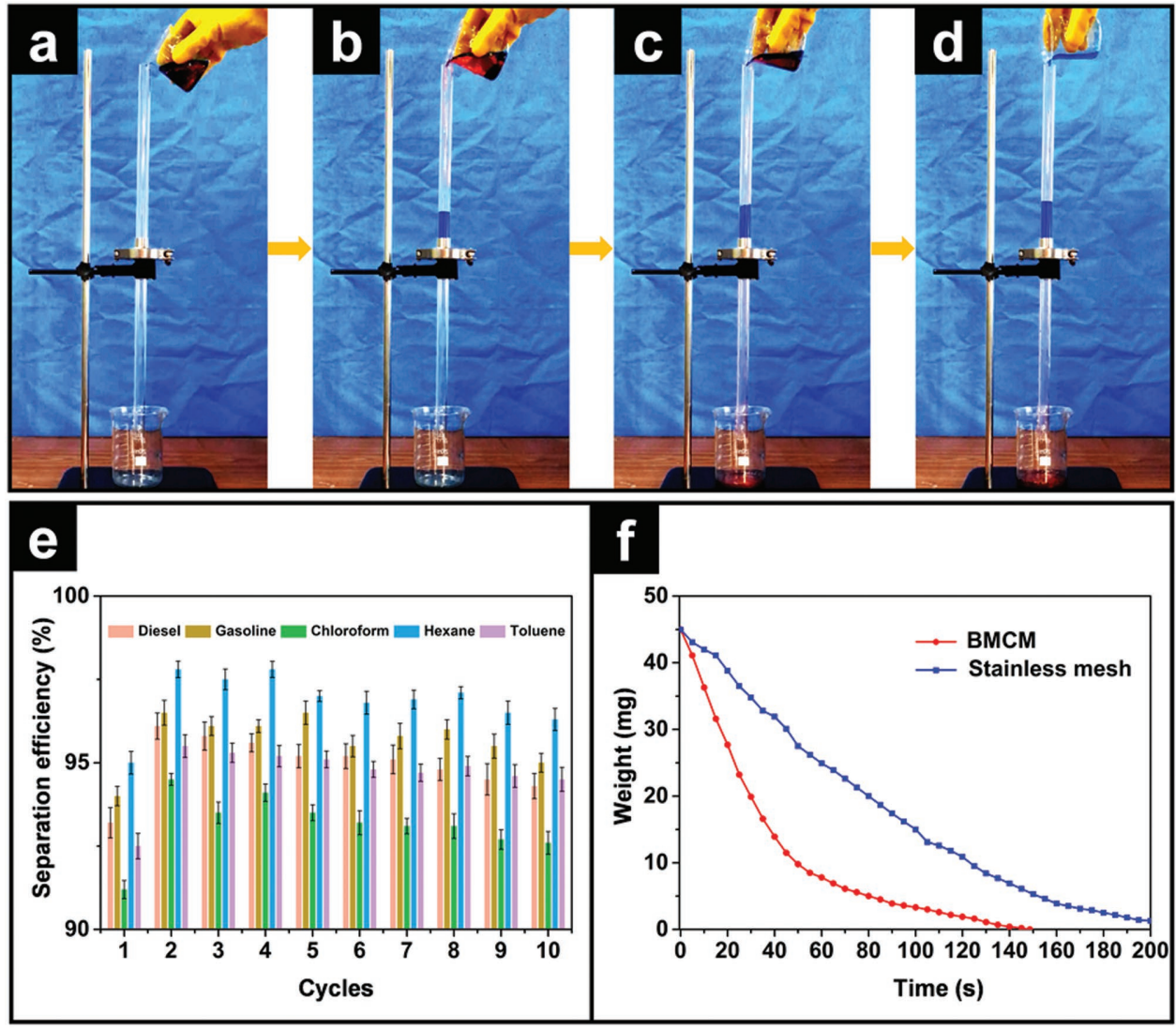

Figure 9. Oil-water separation processes and self-recovery anti-oil-fouling property of the BMCM-based device. a) Before, b,c) among, and d) after the oil-water separation processes. e) Separating efficiency of recycled experiments for separating different oils from water. $f$ ) Self-recovery anti-oil-fouling property of BMCM.

state was characterized by a self-built system which is mentioned in Figure 1g. The tested samples were placed on a high-sensitivity electronic balance in advance. $45 \mathrm{mg}$ oil was dropped onto stainless steel mesh and the BMCM uniformly through a glass capillary, and a high-speed camera was utilized to record the readings changes. Figure 9f showed the residual oil on the stainless mesh (reference membrane) and $\mathrm{BMCM}$ as a function of time $t$. It could be observed that the oil volatilization rate on the stainless steel mesh was relatively stable. It took more than $200 \mathrm{~s}$ for the oil on the stainless steel mesh to evaporate absolutely. The evaporation of oil on the BMCM was much faster than that on stainless steel mesh. Then, the volatilization slowed down since the amount of oil became quite small. At $\approx 148 \mathrm{~s}$, the oil droplets were completely released and the BMCM reverted to the original state, indicating that the MHDS-based BMCM was highly resistant to being fouled by oil, which was conducive for its reutilization. Then, the anti-oil-fouling tests of the BMCM after oil (cyclohexane) contamination and immersion are presented graphically in Figure S6 (Supporting Information). We show in Figure S6a (Supporting Information) the side view of a water droplet that formed a sphere at the oil-solid interface without wetting the BMCM surface; the droplet then rolled off from the surface (Video S6, Supporting Information). As shown in Figure S6b-d (Supporting Information), the water droplets slipped off from the BMCM surface that was contaminated by oil (cyclohexane), indicating anti-oil-fouling properties were retained even after oil contamination (Video S7, Supporting Information). ${ }^{[44]}$

In order to further reveal the internal nonwetting mechanism of the BMCM, one possible reasonable explanation for these findings was that the synergistic effect of both chemical compositions and physical structures of BMCM was the key factor to realize the oil-water separation function (Figure 10). At the molecular level, copper stearate 3D networks composed of hydrophobic alkyl chains $\left(\mathrm{CH}_{3}\left(\mathrm{CH}_{2}\right)_{16} \mathrm{COO}-\right)$ had strong resistance ability for water molecules and absorption capability for chloroform, which was chemically conducive for repelling water droplets and capturing oil droplets. These copper stearate 3D networks acted as intelligent switches for the passage of different liquids. At the nanoscale level, SLCs were generated by dendritic bumps joining with hydrophobic groups in the space between dendritic-like structures, which was inspired by fold stripes in butterfly wings. At the microscale level, copper clusters were made up of dendrites bumps. Copper clusters showed different attitudes toward oil and water, which acted as ridges on the butterfly wings. Microscale copper clusters and nanoscale dendrites bumps together formed the MHDS. Illustrations showed the static microforce analysis of the water molecules and oil molecules. Physically, water molecules were affected by intermolecular force $\left(F_{1}\right)$, repulsion force of long alkyl chains $\left(F_{2}\right)$, surface tension $(\sigma)$, and its own gravity $(G)$. These forces finally reached a balance, 


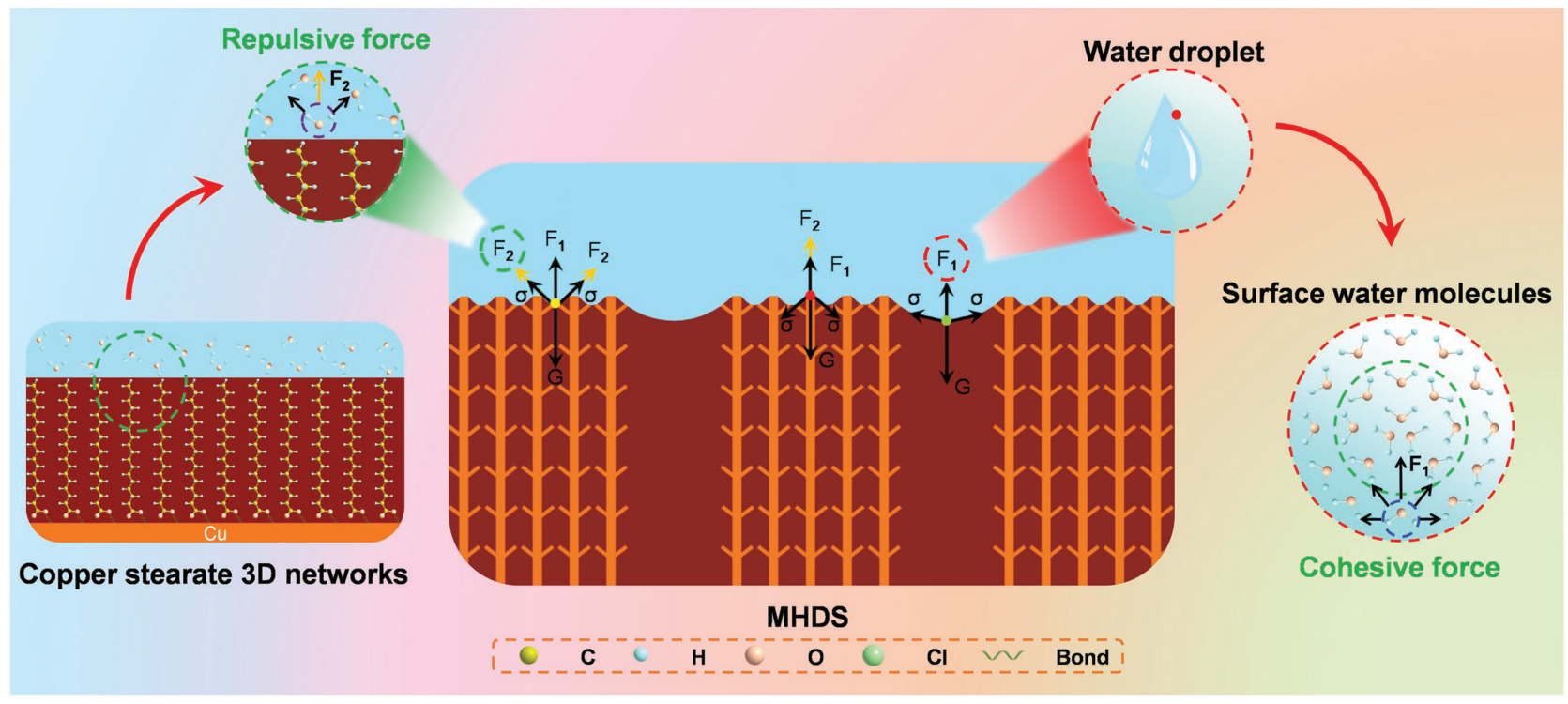

Figure 10. Synergistic effect of chemical compositions and MHDSs of the BMCM, realizing the selective transmission of oil-water mixture. Illustrations show the static microforce analysis of the water molecules and oil molecules. Here, $F_{1}$ is intermolecular force, $F_{2}$ is repulsive force, $\sigma$ is surface tension, and $G$ is gravity.

so that a stable water film was formed on the surface of the MHDS. Chloroforms flowed along the SCLs due to the uneven force field and the air layer was eventually filled up. It was a universal strategy to construct the superhydrophobic and superoleophilic surface by creating rough structures with proper components. Interestingly, the MHDS played a significant role in amplifying the intrinsic wettability of stainless steel film, which dramatically increased the surface roughness. Apparently, it was the hierarchical amplification effect of MHDS that brought big rewards for the achievement of the superhydrophobic and superoleophilic surface.

\section{Conclusion}

In summary, the typical nonwetting performance of T. brookiana butterfly wings was demonstrated. Inspired by this regard, the MHDS-based BMCM was cleverly designed and successfully fabricated on steel mesh substrate via a simple and effective biomimetic fabrication method that combined electroless deposition and subsequent chemical modification. The nonwetting properties of MHDS-based $\mathrm{BMCM}$ were investigated experimentally using optical contact angle measuring device and self-built liquids dropping system. It was confirmed that the MHDS possesses excellent superhydrophobic and superoleophilic properties. The dimensions and distributions of SNWF in BMCM were characterized with the help of field-emission scanning electronic microscopy (FESEM). It was found that the BMCM is composed of molecular-scale copper stearate 3D networks and MHDSs. Meanwhile, a set of optimized models was generated according to the feature sizes of butterfly wings to illustrate the biomimetic fabrication process and the underlying oil-water separation mechanism. Moreover, the cycling tests demonstrated that BMCM possessed excellent recyclability because the separation efficiency remained higher than
93\% for five different oils after more than ten-time repeats. The separation methodology was solely gravity-driven and consequently expected to be highly energy-efficient. Antioil-fouling behaviors of the BMCM were examined carefully. It was confirmed that the BMCM possesses superior self-recovery anti-oil-fouling property $(\approx 150 \mathrm{~s})$, which was conducive for BMCM to keep a high separation efficiency for oil-water mixtures continuously. We anticipate that the BMCM may suggest great potential value for reclaiming oil from polluted nature water area caused by shipwreck or leakage. The bioinspired oil-water separation methodology could also have numerous applications such as the wastewater treatment, fuel purification, and the separation of commercially relevant oily water. More importantly, the diverse bioinspired materials with excellent physicochemical properties may inspire more scientists and engineers to focus on mimicking natural structures in a simple and effective methodology and to design more ingenious engineering products with desirable functionalities in the future.

\section{Experimental Section}

Materials: Wings of mature T. brookiana butterfly, from the tropical rain forest, were taken as the biological prototypes. Butterfly specimens were purchased commercially from Dieyu Corporation (Shanghai, China). In this experiment, the fore wings (because of their larger investigated areas) were selected as test specimens and their oil-water separation function was investigated. In order to confirm that the butterfly wings were clean, each specimen was soaked with aether for $15 \mathrm{~min}$ to remove proteins and fattiness on the surface. Then, the specimens were dried naturally. The stainless steel meshes were obtained from Changzhou Tengda Hardware Store. The pores of mesh had diameters of $\approx 115 \mu \mathrm{m}$. Stearic acid was purchased from Tianjin Huadong Reagent Works. Methylene blue and Sudan III as the coloring agents were obtained from 
Tianjin kangfu Fine Chemical Co., Ltd. Diesel and gasoline were the products of SINOPEC. All other analytic grade reagents were purchased from Beijing Chemical Works. This included copper chloride, sulfuric acid, anhydrous ethanol, chloroform, hexane, toluene, and acetone. All chemicals were used as received without further purification.

Fabrication Process of the BMCM with MHDSs: To remove the oxide film and organic matters, stainless steel meshes were rinsed using ultrasonic cleaner for $7 \mathrm{~min}$ in a solution of acetone, anhydrous ethanol, and distilled water, respectively. After drying, the meshes were immersed in an aqueous solution of $\mathrm{CuCl}_{2}(1.5 \mathrm{~m})$ and $\mathrm{H}_{2} \mathrm{SO}_{4}(0.25 \mathrm{~m})$ at room temperature for an immersion time of $15 \mathrm{~s}$. After a period of reactions, samples were removed from the solution and washed with a sufficient amount of distilled water. Then, the resulting copper meshes were dried in a vacuum drying oven at $170{ }^{\circ} \mathrm{C}$ for $120 \mathrm{~min}$. The as-prepared meshes were immersed in an ethanol solution $(0.1 \mathrm{~m})$ of stearic acid for $80 \mathrm{~min}$ under ambient condition. After modified by stearic acid, samples were rinsed by sufficient anhydrous alcohol and then were dried in a vacuum oven at $80^{\circ} \mathrm{C}$ for $30 \mathrm{~min}$.

Characteristics of Butterfly Wing Surface and Prepared Sample: The 2D morphologies and structures of butterfly wing scales and as-prepared meshes were obtained with the help of digital video camera (EOS7D, CANON) and FESEM (JSM-6700F, JEOL) at an accelerating voltage of $2.0 \mathrm{kV}$. In addition, the element types and content analysis of a single scale surface and prepared samples were characterized by an EDS equipped on SEM. The average surface roughness of stainless steel meshes and the BMCM was measured with the help of a 3D microscope system with superwide depth of field (VHX-5000, KEYENCE). ${ }^{[45,46]}$ XRD measurements were carried out with a Bruker-AXS X-ray diffractometer system, recorded in the lower angle. The chemical bonds of butterfly wing scales and samples were examined by FIIR spectroscopy (JACSCO). Wettability of the specimens was examined using an optical contact angle measuring device (OCA20 data physics, Germany). Water droplets $(5 \mu \mathrm{L})$ were carefully dropped onto the surfaces, and the average static contact angle value was obtained by measuring five different positions of each surface. The static contact angles and the low adhesion force of the butterfly wing surfaces were obtained in this experiment, which proved the superhydrophobic, superoleophylic, and self-cleaning properties of butterfly wings. The impacting processes of water and oil onto tested membranes (butterfly wing surface, prepared samples, and stainless steel meshes) were monitored using a 3D microscope system with superwide depth of field and the high-speed camera (video camera Phantom V711, Vision Research, Inc., films shot at 1000 frames $\mathrm{s}^{-1}$ ), for macroscopic and microcosmic observations, respectively. ${ }^{[47,48]}$

Oil/Water Mixture Separation Experiments: The device consists of two flanges, retort stands, two glass tubes, beakers, and tested membranes. The butterfly wing specimens and as-prepared samples were fixed between two flanges. A mixture of water and oil was poured onto the membrane through a glass tube. Oil $(25 \mathrm{~mL})$ was poured into water $(25 \mathrm{~mL})$ contained in a beaker. Meantime, in order to distinguish between oil and water, they were colored by Sudan III and methylene blue, respectively. The permeated liquid was collected in a beaker. The driving force during the separation process was its own gravity. The whole process was repeated ten times.

\section{Supporting Information}

Supporting Information is available from the Wiley Online Library or from the author.

\section{Acknowledgements}

This work was supported by the National Natural Science Foundation of China (Nos. 51325501, 51505183, and 51290292), China Postdoctoral Science Foundation Funded Project (Project No. 2015M571360), Science and Technology Development Project of Jilin Province (No. 20170520095JH), and Graduate Innovation Fund of Jilin University (No. 2016020).

\section{Conflict of Interest}

The authors declare no conflict of interest.

[1] X. Hou, Y. H. Hu, A. Grinthal, M. Khan, J. Aizenberg, Nature 2015, $519,70$.

[2] A. K. Kota, G. Kwon, W. Choi, J. M. Mabry, A. Tuteja, Nat. Commun. 2012, 3, 1025.

[3] K. Li, J. Ju, Z. X. Xue, J. Ma, L. Feng, S. Gao, L. Jiang, Nat. Commun. 2013, 4, 2276.

[4] H. G. Zhu, D. Y. Chen, W. An, N. J. Li, Q. F. Xu, H. Li, J. H. He, J. M. Lu, Small 2015, 39, 5222.

[5] B. Wang, Z. G. Guo, Appl. Phys. Lett. 2013, 103, 063704.

[6] B. Wang, W. X. Liang, Z. G. Guo, W. M. Liu, Chem. Soc. Rev. 2015, $44,336$.

[7] G. Kwon, A. K. Kota, Y. X. Li, A. Sohani, J. M. Mabry, A. Tuteja, Adv. Mater. 2012, 24, 3666.

[8] Q. L. Ma, H. F. Cheng, Y. F. Yu, Y. Huang, Q. P. Lu, S. K. Han, J. Z. Chen, R. Wang, A. G. Fane, H. Zhang, Small 2017, 13, 1700391.

[9] D. Hu, X. Y. Li, L. Li, C. F. Yang, Sep. Purif. Technol. 2015, 149, 65.

[10] C. Y. Yan, Z. Y. Ji, S. H. Ma, X. L. Wang, F. Zhou, Adv. Mater. Interfaces 2016, 3, 1600015.

[11] Z. A. Liu, X. Y. Wang, M. Q. Gao, J. L. Song, L. Huang, J. Y. Liu, X. Liu, W. Xu, D. Y. Zhao, RSC Adv. 2016, 6, 88001.

[12] R. Du, Q. C. Zhao, P. Li, H. Y. Ren, X. Gao, J. Zhang, ACS Appl. Mater. Interfaces 2016, 8, 1025.

[13] L. Zhang, L. L. Li, Z. M. Dang, J. Colloid Interface Sci. 2016, 463, 266.

[14] A. V. Dudchenko, J. Rolf, L. Shi, L. Olivas, W. Y. Duan, D. Jassby, ACS Nano 2015, 9, 9930.

[15] X. B. Li, H. X. Xu, J. T. Liu, J. Zhang, J. Li, Z. L. Gui, Sep. Purif. Technol. 2016, 165, 101.

[16] J. Saththasivam, K. Loganathan, S. Sarp, Chemosphere 2016, 144,671 .

[17] J. Li, L. Shi, Y. Chen, Y. B. Zhang, Z. G. Guo, B. I. Su, W. M. Liu, J. Mater. Chem. 2012, 22, 9774.

[18] Z. J. Wang, G. J. Liu, S. S. Huang, Angew. Chem., Int. Ed. 2016, 55, 14610.

[19] Q. Zhu, Q. M. Pan, F. T. Liu, J. Phys. Chem. C 2011, 115, 17464.

[20] K. S. Liu, L. Jiang, Nanoscale 2011, 3, 825.

[21] J. L. Song, S. Huang, K. Hu, Y. Lu, X. Liu, W. J. Xu, J. Mater. Chem. A 2013, 1, 14783. 
[22] H. Yang, P. H. Pi, Z. Q. Cai, X. F. Wen, X. B. Wang, J. Cheng, Z. R. Yang, Appl. Surf. Sci. 2010, 256, 4095.

[23] Y. Liu, W. G. Yao, X. M. Yin, H. Y. Wang, Z. W. Han, L. Q. Ren, Adv. Mater. Interfaces 2016, 3, 1500723.

[24] Y. Liu, K. T. Zhang, W. G. Yao, C. C. Zhang, Z. W. Han, L. Q. Ren, Ind. Eng. Chem. Res. 2016, 55, 2704.

[25] K. D. Deeng, A. R. Mohamed, S. Bhatia, Chem. Eng. J. 2004, 103, 147.

[26] H. T. Wang, C. Z. Na, Langmuir 2015, 31, 7401.

[27] A. I. Abdulagatov, Y. Yan, J. R. Cooper, Y. Zhang, Z. M. Gibbs, A. S. Cavanagh, R. G. Yang, Y. C. Lee, S. M. George, ACS Appl. Mater. Interfaces 2011, 3, 4593.

[28] N. Hordy, N. Y. Mendoza-Gonzalez, S. Coulombe, J. L. Meunier, Carbon 2013, 63, 348.

[29] S. C. Niu, B. Li, Z. Z. Mu, M. Yang, J. Q. Zhang, Z. W. Han, L. Q. Ren, J. Bionic Eng. 2015, 12, 170.

[30] C. Sanchez, H. Arribart, M. M. Guille, Nat. Mater. 2005, 4, 277.

[31] E. Munch, M. E. Launey, D. H. Alsem, E. Saiz, A. P. Tomsia, R. O. Ritchie, Science 2008, 322, 1516.

[32] N. J. Shirtcliffe, G. McHale, M. I. Newton, Langmuir 2009, 25, 14121.

[33] L. Feng, Y. Zhang, J. Xi, Y. Zhu, N. Wang, F. Xia, L. Jiang, Langmuir 2008, 24, 4114.

[34] X. Gao, L. Jiang, Nature 2004, 432, 36.

[35] Z. W. Han, Z. Z. Mu, B. Li, Z. Wang, J. Q. Zhang, S. C. Niu, L. Q. Ren, ACS Nano 2016, 10, 8591.

[36] Z. W. Han, B. Li, Z. Z. Mu, M. Yang, S. C. Niu, J. Q. Zhang, L. Q. Ren, Appl. Surf. Sci. 2015, 355, 290.
[37] Z. Xu, K. Yu, B. Li, R. Huang, P. Wu, H. B. Mao, N. Liao, Z. Q. Zhu, Nano Res. 2011, 4, 737.

[38] R. H. Siddique, S. Vignolini, C. Bartels, I. Wacker, H. Holscher, Sci. Rep. 2016, 6, 36204.

[39] Z. W. Han, Z. Z. Mu, B. Li, S. C. Niu, J. Q. Zhang, L. Q. Ren, Small 2016, 12, 713.

[40] Q. F. Cheng, M. Z. Li, Y. M. Zheng, B. Su, S. T. Wang, L. Jiang, Soft Matter 2011, 7, 5948.

[41] C. C. Liu, J. Ju, Y. M. Zheng, L. Jiang, ACS Nano 2014, 8, 1321.

[42] S. D. Yang, L. Chen, L. Mu, B. Hao, J. T. Chen, P. C. Ma, RSC Adv. 2016, 6, 4889.

[43] M. Rana, J. T. Chen, S. D. Yang, P. C. Ma, Adv. Mater. Interfaces 2016, 3, 1600128.

[44] Y. Lu, S. Sathasivam, J. L. Song, C. R. Crick, C. J. Carmalt, I. P. Parkin, Science 2015, 347, 6226.

[45] M. Miwa, A. Nakajima, A. Fujishima, K. Hashimoto, T. Watanabe, Langmuir 2000, 16, 5754.

[46] B. J. Shieh, F. J. Hou, Y. C. Chen, H. M. Chen, S. P. Yang, C. C. Cheng, H. L. Chen, Adv. Mater. 2010, 22, 597.

[47] C. R. Crick, J. A. Gibbins, I. P. Parkin, J. Mater. Chem. A 2013, 1, 5943.

[48] J. C. Bird, R. Dhiman, H. M. Kwon, K. K. Varanasi, Nature 2013, 503, 385.

Received: April 6, 2017

Revised: May 24, 2017

Published online: July 17, 2017 